NASA Technical Memorandum 100212

\title{
High Temperature Metal Matrix Composites for Future Aerospace Systems
}

\author{
(NASA-TH-100212) HIGH TEHPERATURE AETAL \\ $88-10938$ \\ MATRIX COHPOSITES FOR FOTORE ABROSPACE \\ SYSTENS (NASA) $18 \mathrm{p}$ AVAII: NTIS HC \\ A03/AF AO1 \\ CSCL $11 \mathrm{~F}$ \\ Onclas \\ G3/26 0106484
}

Joseph R. Stephens

Lewis Research Center

Cleveland, Ohio

Prepared for the

ASM International Composite Session

Cincinnati, Ohio, October 13-15, 1987 


\title{
HIGH TEMPERATURE METAL MATRIX COMPOSITES
}

\author{
FOR FUTURE AEROSPACE SYSTEMS
}

\author{
Joseph R. Stephens \\ National Aeronautics and Space Administration \\ Lewis Research Center \\ Cleveland, Ohio 44135
}

SUMMARY

The objective of our research on metal matrix composites and intermetallic matrix composites is to understand their behavior under anticipated future operating conditions envisioned for aerospace power and propulsion systems of the 21 st century. Extremes in environmental conditions, high temperature, long operating lives, and cyclic conditions dictate that our test evaluations not only include laboratory testing, but simulated flight conditions. This paper will discuss the various processing techniques we employ to fabricate composites, the basic research, underway to understand the behavior of high temperature composites, and relate some of this research to future aerospace systems.

\section{INTRODUCTION}

Aerospace propulsion and power systems for the 1990s and into the 21 st century will place ever increasing demands on load bearing materials. The emphasis on putting greater payloads into space, provide electrical power for space experiments and to meet the demands of manned and unmanned spacecraft, and to fly at hypersonic velocities will require materials that are light weight and that can withstand high temperatures for long periods of time in hostile environments. To meet these demands NASA Lewis Research Center has undertaken an aggressive research program on advanced materials to provide a technology base for future aerospace systems. A major portion of this program is focused on metal matrix composites (MMC) and intermetallic matrix composites (IMC). It is the purpose of this paper to describe the basic and applied research that we have underway on MMC/IMC technology to meet the demands of major NASA and national programs such as electrical power systems for the Space Station (fig. 1), engines for advanced Space Shuttles (fig. 2), and engines for the National Aerospace Plane (NASP) as illustrated in figure 3.

Each of the aforementioned programs brings with it a special set of operational requirements which tax the capabilities of the composite materials. For example, as shown in figure 4, space power systems for such applications as the Space Station are planned to operate for 7 to 10 years with very few heat up and cool down cycles and in the nonaggressive environment of space. However, for maximum power efficiency operating temperatures may be in excess of $1450^{\circ} \mathrm{C}\left(2640^{\circ} \mathrm{F}\right)$ throughout the life of the power system and life will be creep limited. Low weight is a premium to minimize the number of launches required to put the power system in space. Space propulsion systems will be required to function in terms of minutes with probably less than 100 cycles, but in an extremely aggressive environment which may be either reducing or oxidizing throughout the life of the propulsion system depending upon the fuel 
and operating conditions. Temperatures may go from cryogenic to in excess of $1200^{\circ} \mathrm{C}\left(2190^{\circ} \mathrm{F}\right)$ in a matter of seconds so that thermal-mechanical fatigue becomes the life limiting factor for space propulsion systems. In contrast, aero propulsion systems will operate for thousands of hours with a similar number of cycles in an oxidizing-corrosive environment. To achieve high efficiency, material temperatures may reach $1650^{\circ} \mathrm{C}\left(3000^{\circ} \mathrm{F}\right)$ and will fluctuate during the course of a flight by several hundred degrees. Creep-fatigue becomes the life limiting criterion for aeropropulsion systems. Low weight is an important consideration for both aero and space propulsion systems in order to enhance payloads.

Metal matrix composites have the potential to meet these wide variety of requirements as shown in figure 5. By selection of the proper high temperature fiber and combining the fibers with an appropriate matrix, a high temperature, light weight MMC or IMC can be produced with the advantages listed in the figure. Two major disadvantages facing these composite materials are the interdiffusion between fiber and matrix which leads to degradation of the figure strength and the difference in thermal expansion between the fiber and matrix which can lead to degradation of the composite, especially under cyclic conditions. The following sections of this paper will describe the processing techniques to produce MMC and IMC and describe some of the experimental results we have obtained to date.

\section{COMPOSITE PROCESSING}

High temperature MMC and IMC are produced at NASA Lewis primarily by one of two processes. The first of these is the powder cloth technique shown schematically in figure 6 . This is a simple straightforward process that makes use of the matrix material in powder form. The metal or intermetallic powder is mixed with a binder (tefion) and mixed in a stoddard solution, dried, and rolled into a thin, powder cloth. Alternate layers of powder cloth and evenly spaced, oriented fibers are stacked, heated in vacuum to drive off the binder and solution, and then hot pressed. This process has the advantages of using the matrix in powder form which is easily obtained from commercial vendors, employs consolidation equipment that is common to a number of powder metallurgy companies, and volume fraction of fiber content can be controlled. The major disadvantage of this process is the use of a binder and solution which can leave behind detrimental impurities during the processing if their removal is not complete. Typical composites 5 by 15 by $0.075 \mathrm{~cm}$ ( 2 by 6 by 0.030 in.) with a fiber volume fraction of 40 percent are produced by the powder cloth technique.

The second processing technique which was developed at NASA Lewis is the arc spray process shown schematically in figure 7 . A continuous fiber is wound on a drum using a lathe to assure proper spacing. The wound drum is inserted into a vacuum chamber and subsequently arc sprayed with the desired matrix material. The matrix material for this process is in the form of $0.16 \mathrm{~cm}(0.0625$ in.) wire. The wire from two spools of the matrix material is fed into an arc spray gun which strikes an arc between the two wires and with high pressure helium or argon, sprays the molten metal onto the fiber wound drum to form a monotape. Monotapes are stacked with desired fiber orientation and consolidated by hot pressing or hot isostatic pressing (HIPing). This process has the advantages of producing a clean, high purity composite free of 
extraneous materials, is economical, and size is limited only by the size of the vacuum chamber and the drum. Monotapes 0.4 by 1.0 by $0.004 \mathrm{~m}$ ( 16 by 40 by 0.015 in.) have been produced by this process. The primary disadvantage of the arc spray process is the requirement that the matrix material be in the form of wire which in the case of intermetallic compounds, is not always technically feasible.

A third process being adapted to producing composites is the plasma spray technique shown schematically in figure 8 . This process has the advantages of using the matrix material in powder form and does not require the use of binders. Because of the use of small diameter particles at high temperatures, oxygen contamination may be a problem especially with the highly reactive intermetallic compounds such as the aluminides. Because of the many variables in this process such as torch design, torch operation, and powder characteristics, automation and process control are needed to insure uniform reproducible composites.

Each of these processes are followed by a consolidation process such as hot pressing or HIPing. It is normal to prepare flat plates of unidirectional, crossply, or angleply composites. In addition, tubes and more complicated geometries can be produced by the HIP technique. Composite fabrication holds the key to producing a successful composite material. Consolidation is a time-temperature-pressure process ( $f i g$. 9) where the fabrication parameters must be sufficient to consolidate and completely fill the matrix around the fiber and to bond the fiber to the matrix. Insufficient time, temperature, or pressure will not allow consolidation of the composite. Excessive time or temperature can cause increased fiber-matrix reaction and thus fiber strength degradation, while excessive pressure can cause fiber breakage and matrix squeeze-out. Optimization of the process chosen for each composite material plays a major part of our research program.

A final area that we our beginning to address in our research programs is the joining of composite materials. In order to apply advanced composites, actual structures will have to be fabricated. Figure 10 sets forth the problem if proper design of the joint is not taken into consideration. Several techniques are shown that are being explored to overcome this problem.

\section{FUNDAMENTAL RESEARCH}

Advanced fibers. - Since the fiber provides the characteristics that dominate the strength, stiffness, and conductivity of a composite, superior fibers need to be developed. Two particular concerns are the chemical compatibility between fiber and matrix and their thermal expansion mismatch (fig. 11 ). We plan to investigate new high temperature fibers by growing single crystals using a laser floating zone apparatus which operates as shown in figure 12. Fibers with high melting points and thermal expansions similar to those of the matrices that are of interest will be grown and evaluated for high temperature strength, modulus, and compatibility with various matrices.

Matrices. - Intermetallic compounds offer high melting points, light weight, and in the case of aluminides and silicides good oxidation resistance for aero propulsion systems as illustrated for nickel aluminide in figure 13 . 
Alloying and thermomechanical processing are underway to understand factors that may improve the low temperature ductility and high temperature strength of these materials. Figure 14 shows that strengthening of NiAl can be achieved by alloying to form a second phase within the aluminide grains. Other matrices that are currently being explored include $\mathrm{FeAl}, \mathrm{Ti}_{3} \mathrm{Al}+\mathrm{NbAl}_{3}$. For space power and propulsion copper, nickel, and iron alloys along with the refractory metals are being explored as matrices. In particular molybdenumbase alloys are under investigation to improve their high temperature strength and increase their fabricability so that they may be used as either fibers or matrices.

Fiber-matrix interactions. - Chemical reactions or interdiffusion between fiber and matrix can degrade composite properties due to the formation of brittle phases at the interface or the loss of effective fiber diameter with extended exposure times. Figure 15 shows the reaction zone in SiC reinforced FeAl composite. Determination of reaction kinetics as illustrated in figure 16 and effect on properties is currently underway in-house and via of a University Grant. Modeling of the interactions is also being conducted and the effects on properties will be predicted from these models. Similar studies are underway on refractory metal composites.

Environmental resistance. - As mentioned previously, the aluminides and silicides have excellent oxidation resistance due to the formation of adherent $\mathrm{Al}_{2} \mathrm{O} 3$ and $\mathrm{SiO}_{2}$ scales, respectively. However, even these materials are $1 \mathrm{im}-$ ited by temperature and cyclic conditions such that improvement in oxidation resistance is desirable so that these materials can be used in advanced aero propulsion systems. Alloying to improve oxidation resistance is underway as shown in figure 17. Fundamental oxide mapping studies will aid in the development of tertiary additives to stabilize the oxide scales. Dopants such as $\mathrm{Zr}$, $\mathrm{Hf}$, and $Y$ may help reduce oxide spalling. External oxidation resistant coatings and thermal barrier coatings will be explored to further improve the oxidation resistance of the matrix materials.

\section{APPLIED RESEARCH}

Tungsten/niobium composites. - Space power systems for future NASA missions are under development that will require hundreds of kilowatts of electricity. To meet these demands operating temperatures for the power sources are contemplated to be near $1500^{\circ} \mathrm{C}\left(2700^{\circ} \mathrm{F}\right)$. To achieve the long life of 7 to 10 years refractory metal composites appear to hold promise. Figure 18 illustrates this potential based on high temperature tensile tests of $40 \mathrm{vol} \%$ fibers. Long-term creep rupture testing is underway on these composites and fiber-matrix interaction studies are being modeled.

Tungsten/copper composites. - Copper is attractive for heat transfer applications because of its high thermal conductivity. However, its low strength at elevated temperatures limits its utility. Reinforcement with high strength tungsten fibers can overcome the lack of strength problem and if held to a low volume percent, loss in thermal conductivity will be minimized. An application for this composite is in the Space Shuttle combustion liner as illustrated in figure 19. A prototype combustion liner has been tested in one of our rocket engine test facilities and survived over 400 firings of the rocket engine which is over twice the life of OFHC copper and equal to that of 
the current copper alloy now in use on the Space Shuttle Main Engine. We hope to further improve upon this result by modifications of the processing of the composite material and a redesign of the test chamber.

Silicon carbide/titanium aluminide composites. - The light weight, high melting point of $\mathrm{Ti}_{3} \mathrm{Al}$ makes it an attractive candidate material for aircraft propulsion systems. Research by the Air Force has shown that $\mathrm{Nb}$ additions improve the room temperature ductility of this material. Reinforcement by a high-strength 11 ght-weight fiber offers the potential of further increasing the use temperature of this material. Results of tensile testing in air have shown the advantage of this composite over superalloys as shown in figure 20 . Again fiber-matrix interaction is of concern for long term use and as shown in figure 21 this composite may be 1 imited to about $980^{\circ} \mathrm{C}\left(1800^{\circ} \mathrm{F}\right)$. Thermal expansion mismatch between fiber and matrix may further be a limiting criterion for the aluminide composite material.

\section{CONCLUDING REMARKS}

Metal matrix and intermetallic matrix composites offer some unique combinations of material properties for future aerospace power and propulsion systems. NASA Lewis along with other government laboratories, national laboratories, and industrial laboratories are addressing the issues that may be critical to their application as high temperature structural materials. Certainly advanced fiber development is at the top of this list. Thermal expansion mismatch, fiber-matrix compatibility, thermal cycling, and environmental resistance all have to be addressed for each MMC and IMC under conditions anticipated for their use. Our research is focused on the se issues for a variety of composite materials under a broad range of proposed operating conditions. 


\section{COMAT EAOY IS

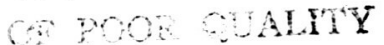

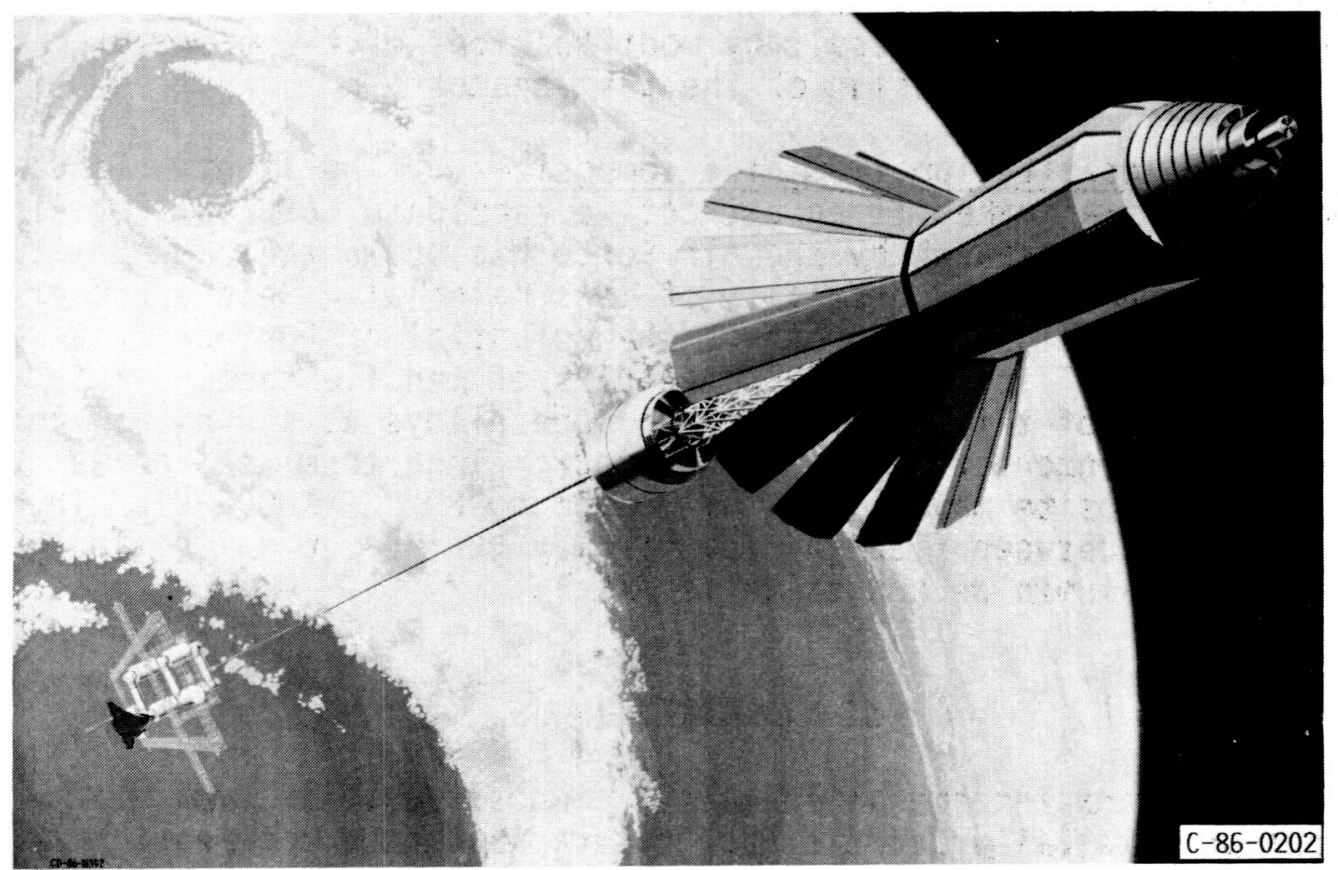

FIGURE 1. - ARTIST'S CONCEPIION OF THE SP-100 NUCLEAR POWER SOURCE FOR THE SPACE STATION.

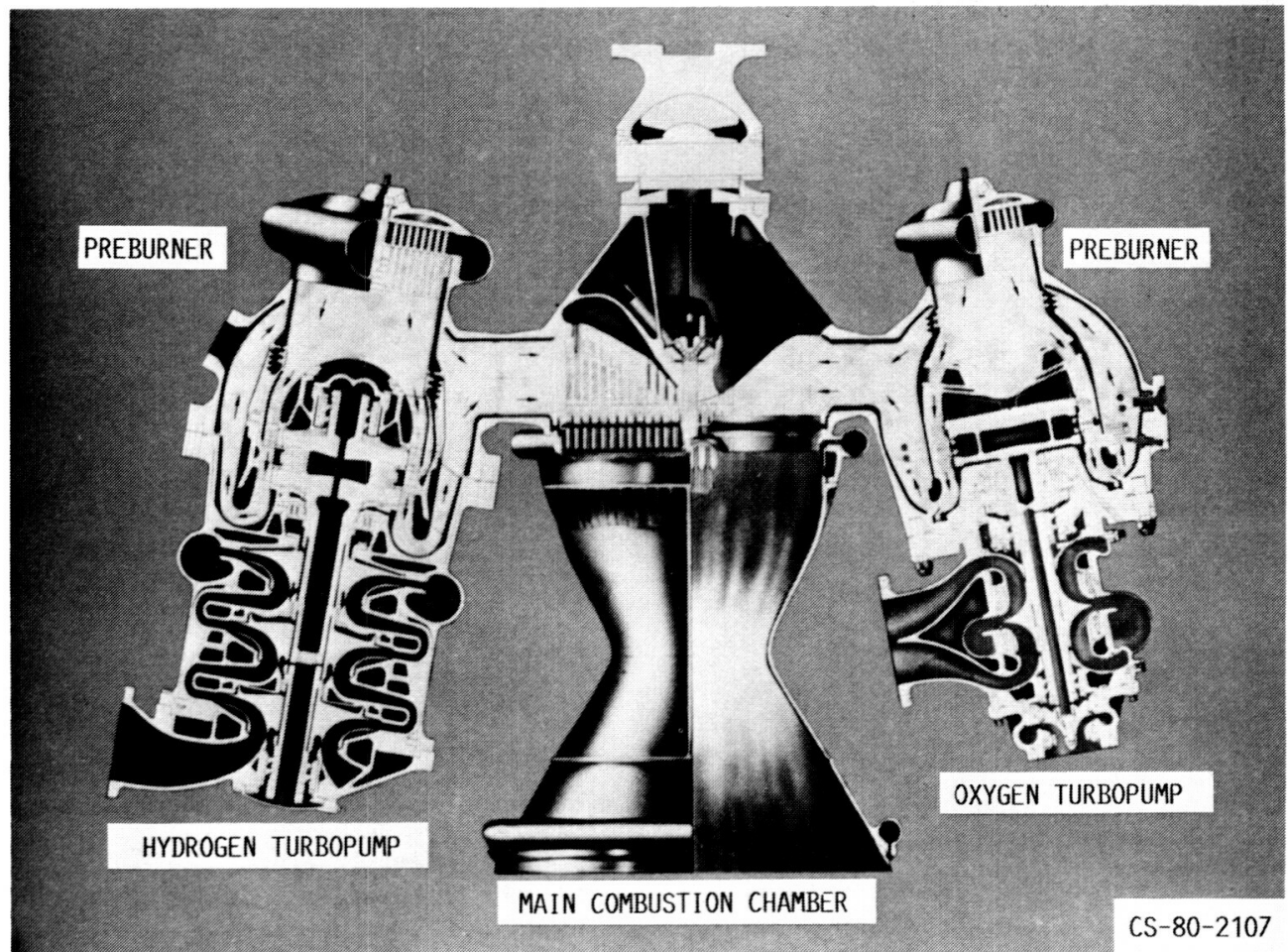

FIGURE 2. - SCHEMATIC REPRESENTATION OF THE SPACE SHUTTLE MAIN ENGINE. 


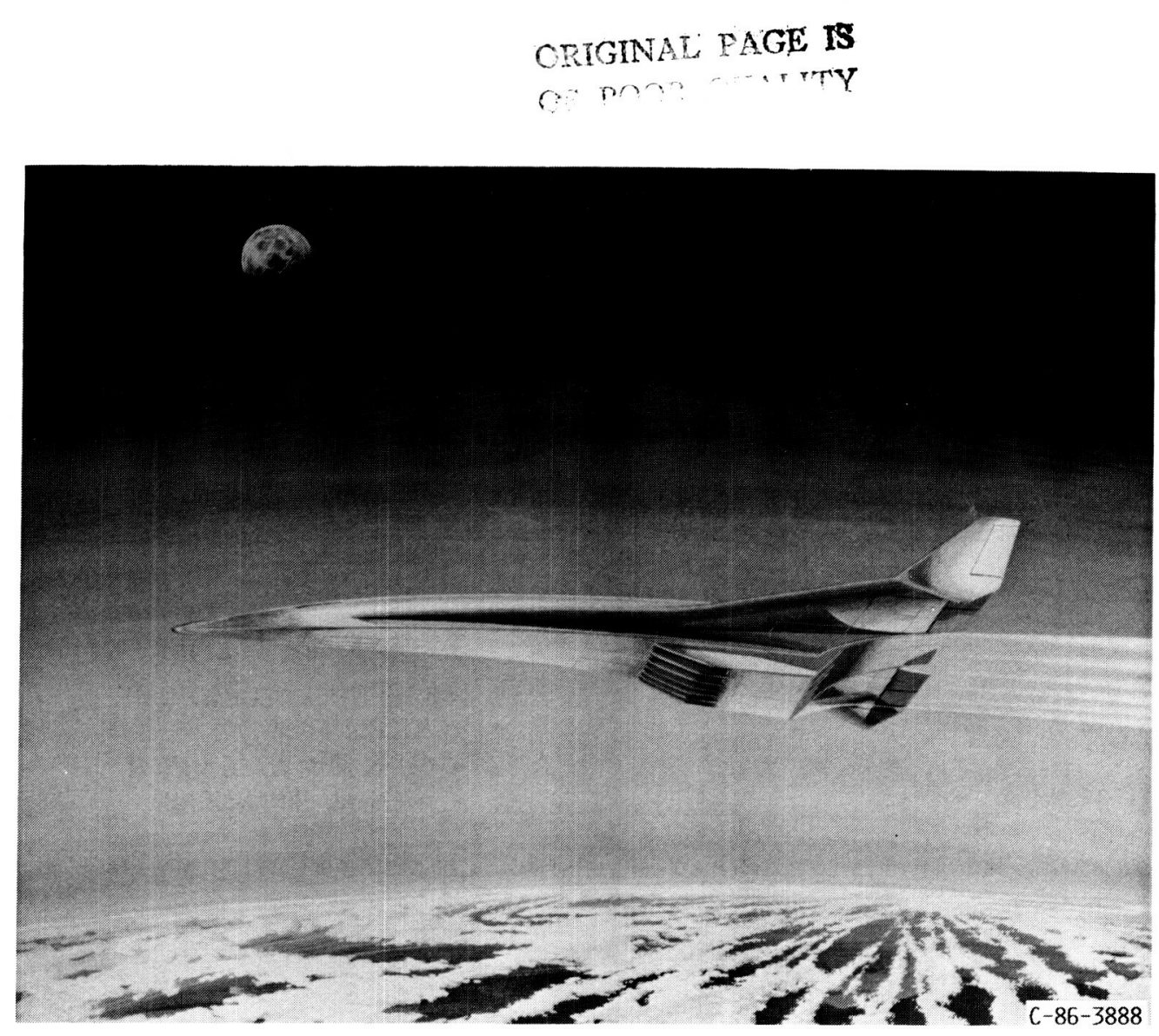

FIGURE 3. - ARTIST'S RENDERING OF THE NATIONAL AEROSPACE PLANE.

\begin{tabular}{|c|c|c|c|}
\hline REQUIREMENT & $\begin{array}{l}\text { SPACE } \\
\text { POWER }\end{array}$ & $\begin{array}{c}\text { SPACE } \\
\text { PROPULSION }\end{array}$ & $\begin{array}{c}\text { AERO } \\
\text { PROPULSION } \\
\end{array}$ \\
\hline LIFE & > SEVEN YEARS & MINUTES & THOUSAND(S) HOURS \\
\hline CYCLES & $<$ TEN & $>$ FIFTY & THOUSANDS \\
\hline ENVIRONMENT & VACUUM & REDUCING/OXIDIZING & OXIDIZING \\
\hline TEMPERATURE & HIGH, SUSTAINED & BURST & VARIABLE \\
\hline WEIGHT & LOW & LOW & LOW \\
\hline $\begin{array}{l}\text { LIFE CONTROLLED } \\
\text { BY STRESS }\end{array}$ & CREEP & FATIGUE & CREEP-FATIGUE \\
\hline
\end{tabular}

$60-87-28892$

FIGURE 4. - FUTURE REQUIREMENTS IMPOSED UPON METAL MATRIX COMPOSITES. 


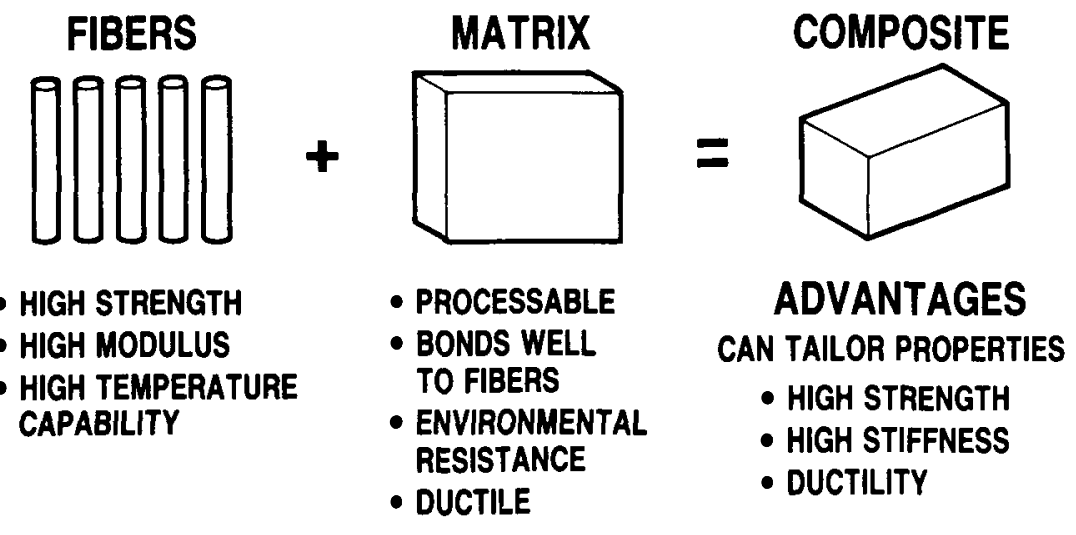

\section{DISADVANTAGES}

- SOMETIMES DEGRADED BY INTERDIFFUSION

- CAN NOT ALWAYS MATCH

THERMAL EXPANSIONS

FIGURE 5. - METAL MATRIX COMPOSITES CONCEPT LISTING THEIR ADVANTAGES AND DISADVANTAGES.

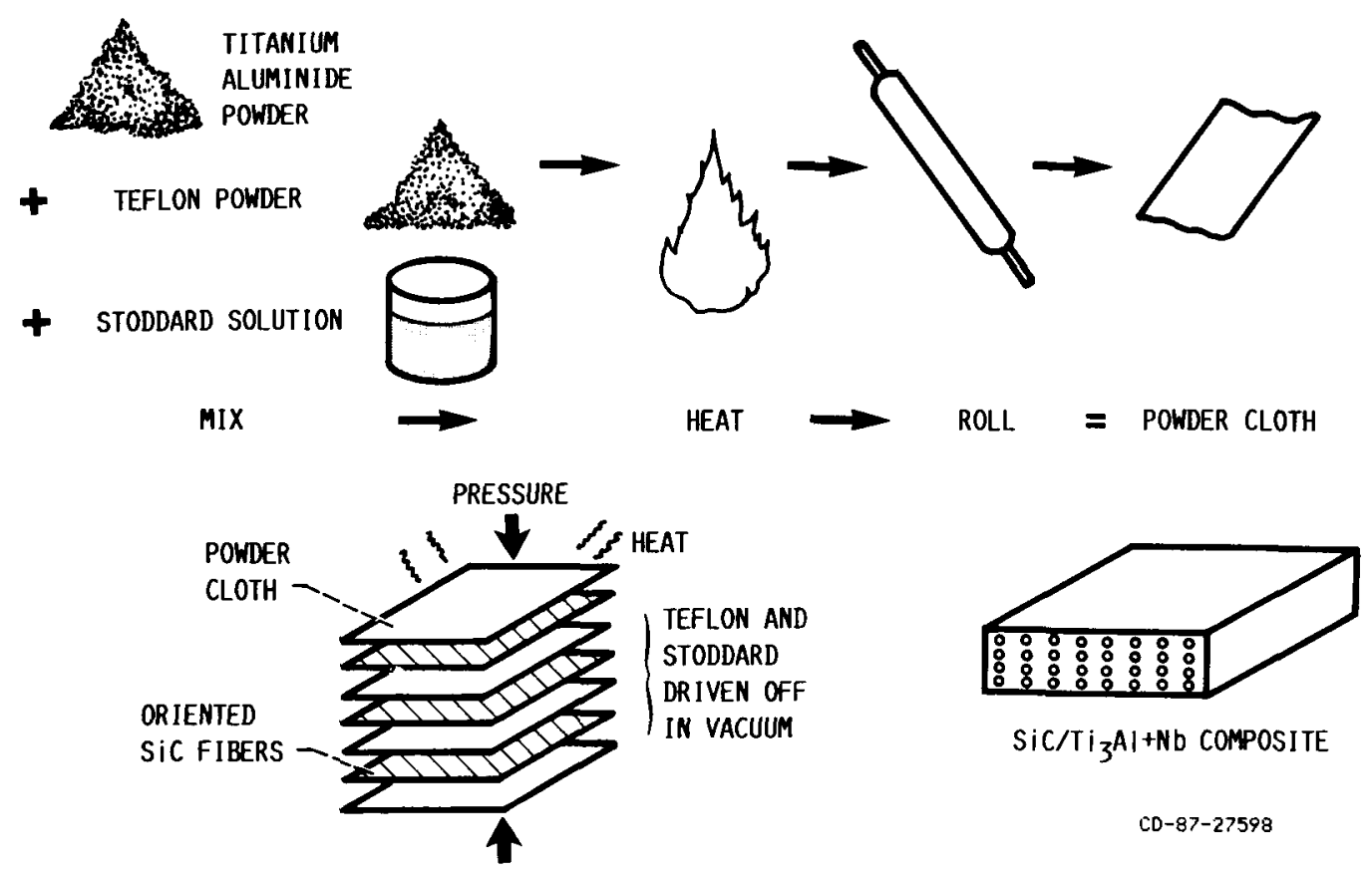

FIGURE 6. - POWDER CLOTH TECHNIQUE USED TO PRODUCE INTERMETALLIC MATRIX COMPOSITES. 


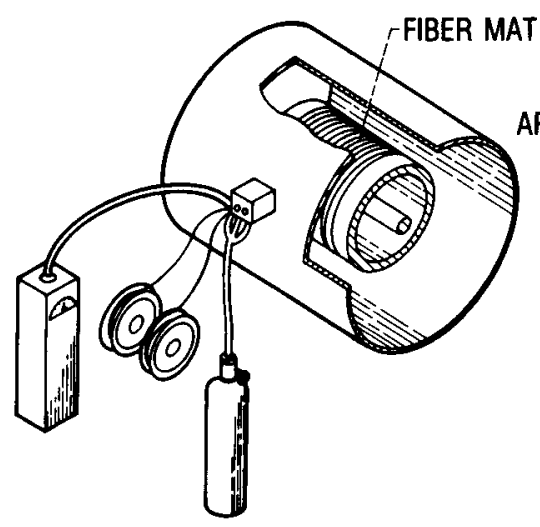

OVERALL VIEW

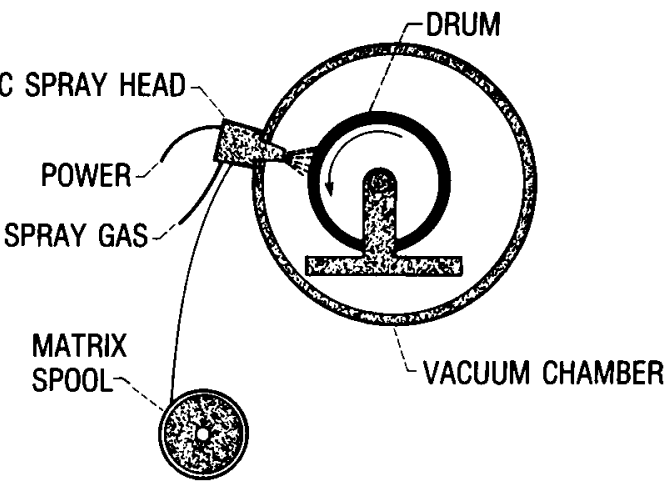

SCHEMATIC OF OPERATION

$C D-87-26390$

FIGURE 7. - ARC SPRAY TECHNIQUE USED TO PRODUCE METAL MATRIX COMPOSITES.

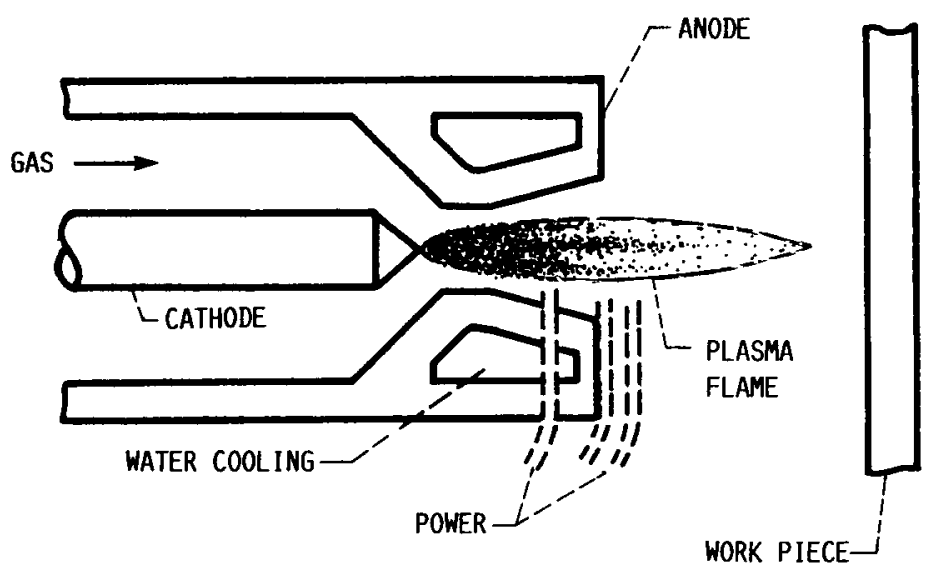

FIGURE 8. - PLASMA SPRAY TECHNIQUE PLANNED FOR PREPARING METAL MATRIX AND INTERMETALLIC MATRIX COMPOSITES.

PROPERTY (TENSILE, CREEP, FATIGUE STRENGTH)

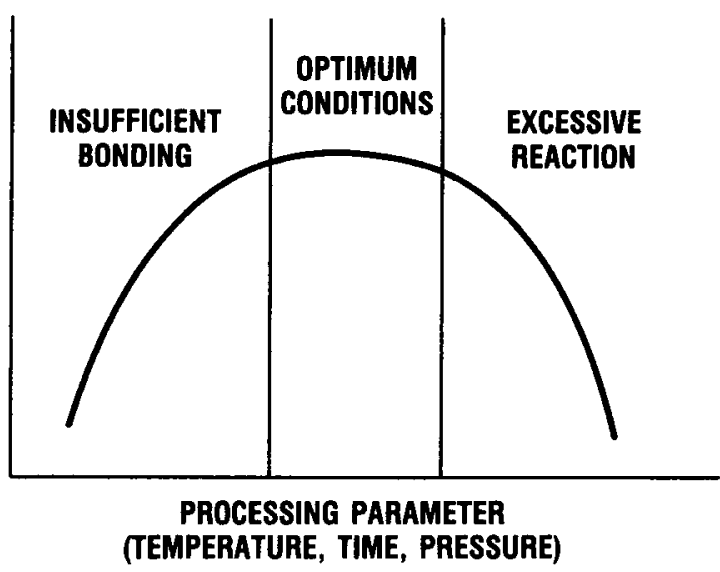

CD-87-26403

FIGURE 9. - OPTIMIZATION OF FABRICATION PARAMETERS IS CRITICAL TO ACHIEVING MAXIMUM PROPERTIES. 
PROBLEM

FIBERS CARRY MAJOR PORTION OF LOAD

IN COMPOSITES. JOINT CAN REPRESENT A

LINE OF DISCONTINUITY IN FIBERS THAT

CAN RESULT IN LOW STRENGTH

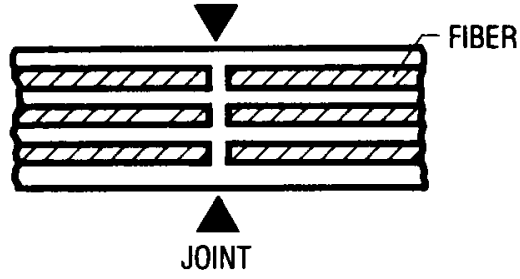

\section{SOLUTION}

- LOCATE JOINTS IN LOWER STRESS AREAS.

- DESIGN JOINT TO PROVIDE TRANSFER OF LOAD FROM FIBER TO FIBER ACROSS JOINT SUCH AS:

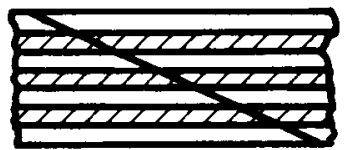

SCARF

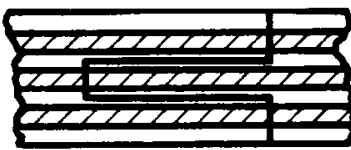

TONGUE IN GROOVE

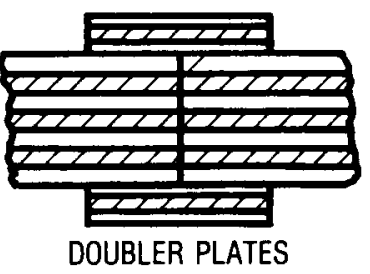

CD-87-26402

FIGURE 10. - SUGGESTED JOINING SCHEMES TO ACHIEVE A STRONG BOND IN COMPOSITE MATERIALS.

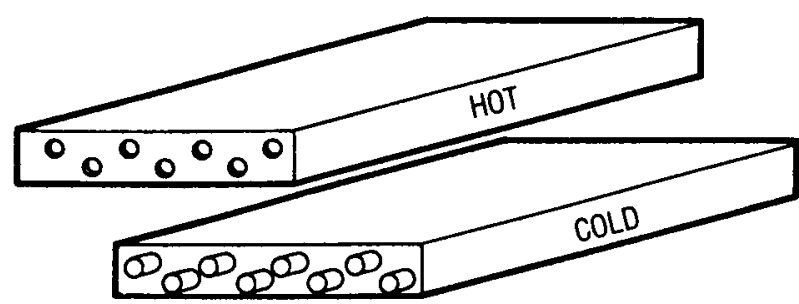

- THERMAL CYCLING EFFECTS INCREASED BY THERMAL EXPANSION MISMATCH

ADDITIONAL STRAIN $=\left(\alpha_{M}-\alpha_{F}\right) \Delta T$

Co-87-26412

FIGURE 11. - THERMAL EXPANSION MISMATCH BETWEEN FIBER AND MATRIX WILL LIMIT THERMAL CYCLIC RESISTANCE OF METAL MATRIX COMPOSITES. 


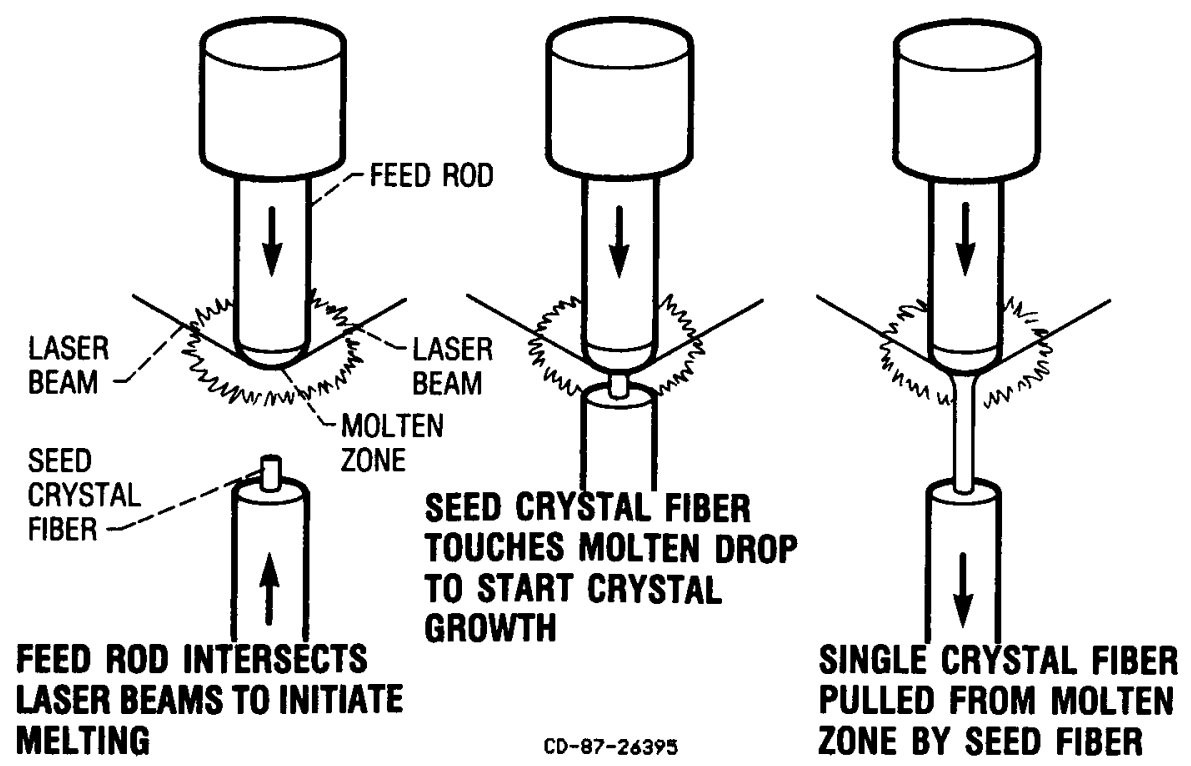

FIGURE 12. - LASER FIBER GROWTH FACILITY WILL BE USED TO GROW ADVANCED FIBERS.

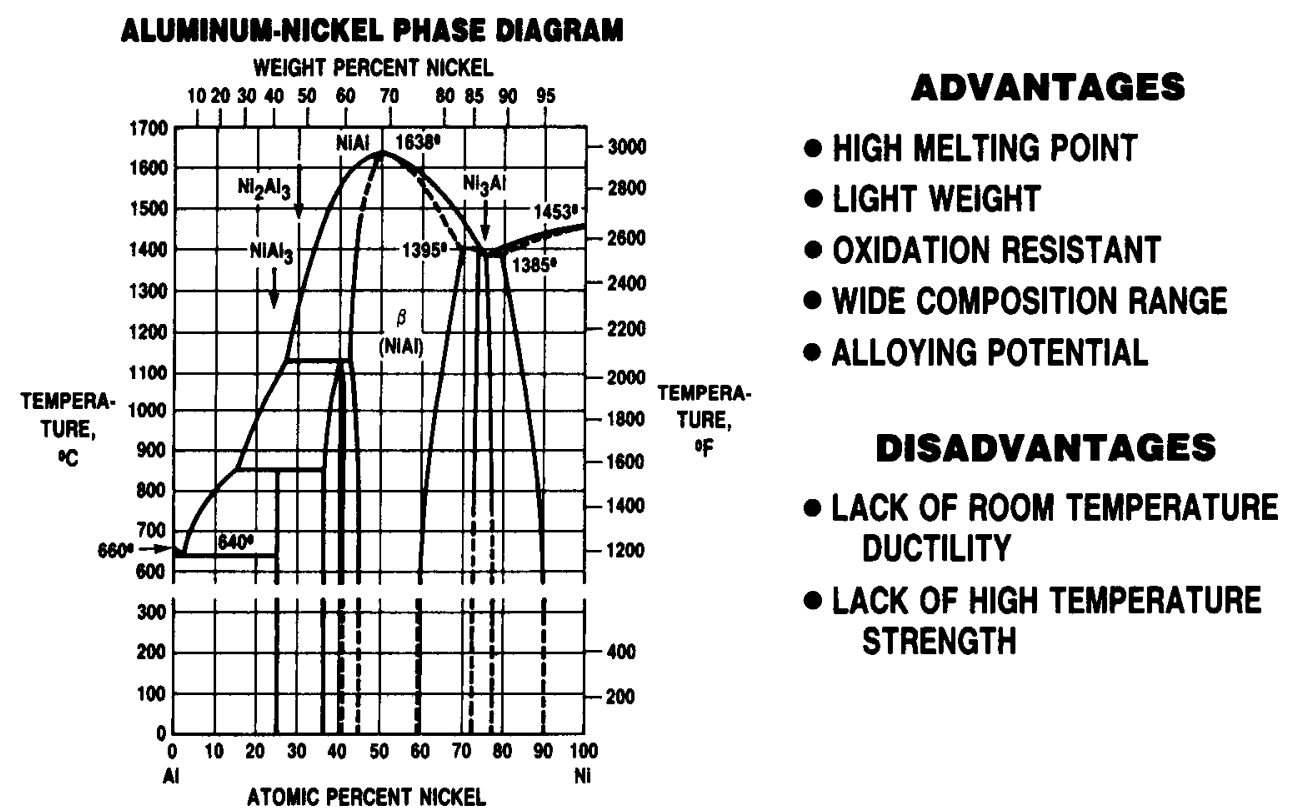

FIGURE 13. - PHASE DIAGRAM FOR THE NICKEL ALUMINUM SYSTEM SHOWING THE HIGH MELTING TEMPERATURE OF THE EQUIATOMIC INTERMETALLIC COMPOUND. 


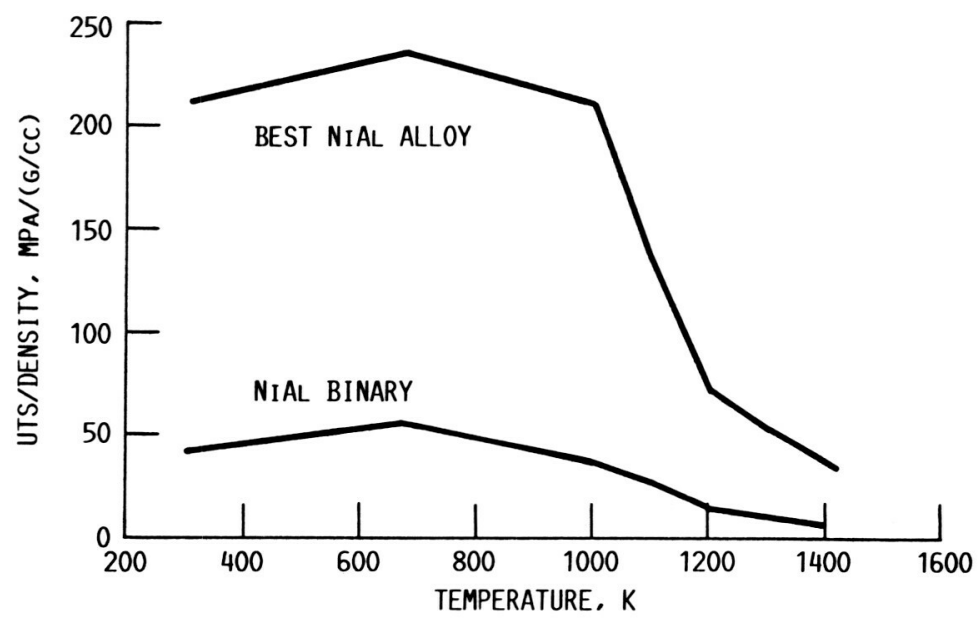

FIGURE 14. - STRENGTHENING OF NICKEL ALUMINIDE CAN BE ACHIEVED BY ALLOYING.

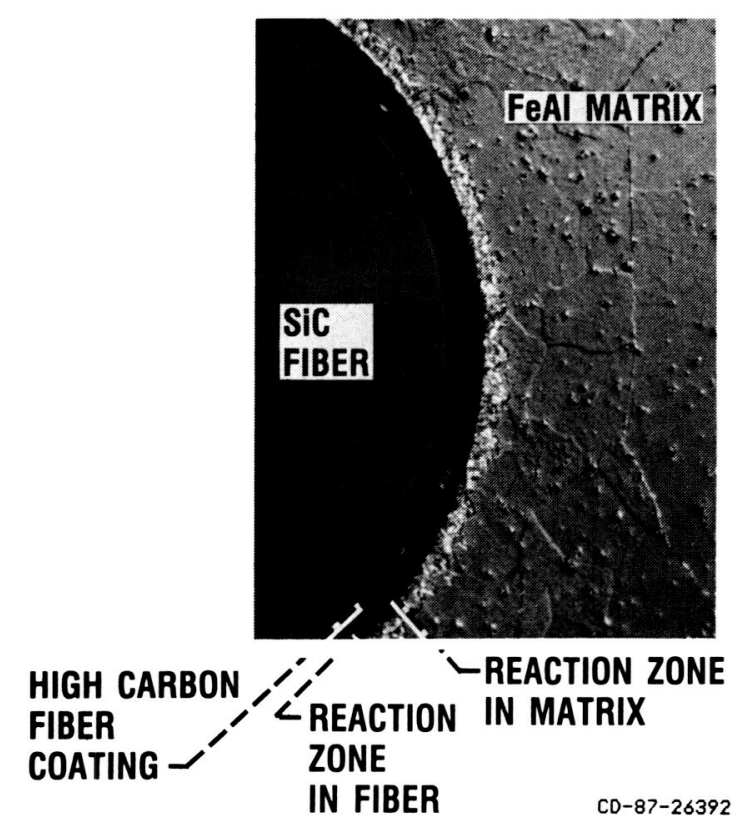

FIGURE 15. - FIBER-MATRIX INTERACTION CAN OCCUR DURING PROCESSING OF A COMPOSITE. 


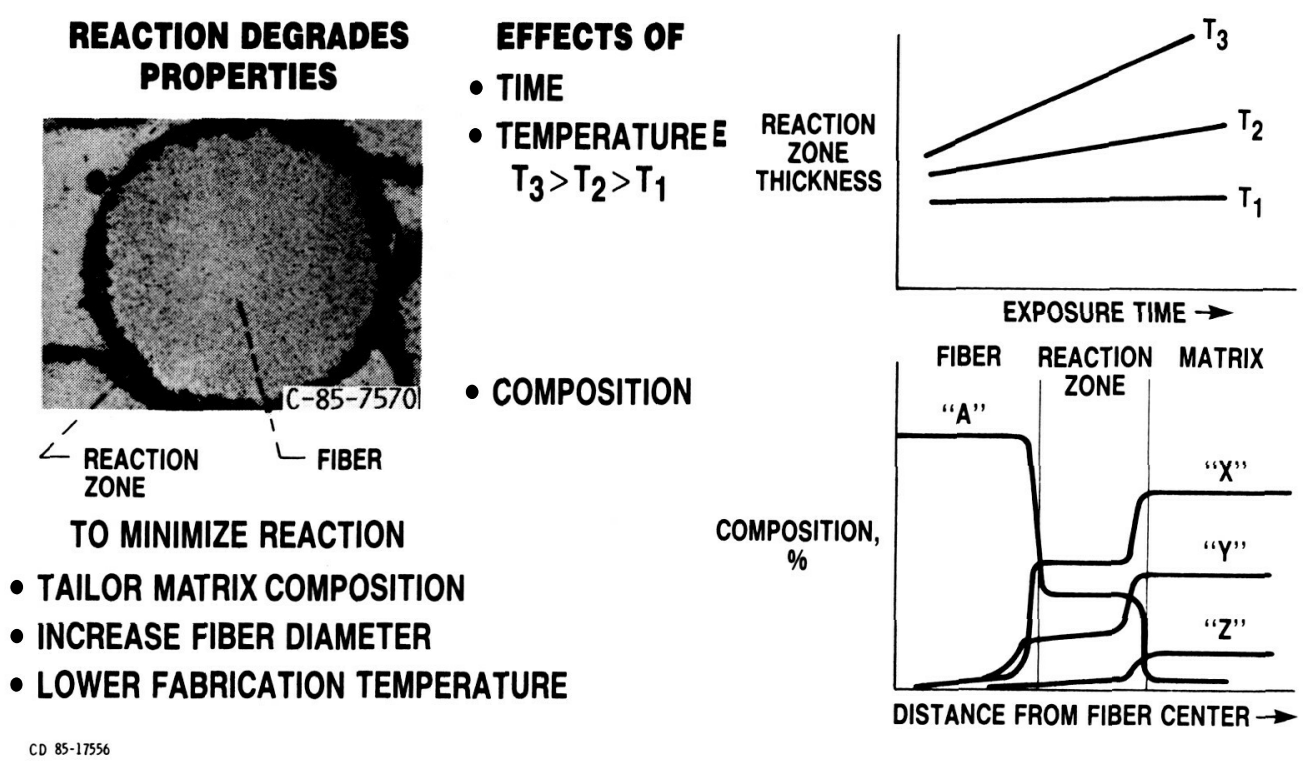

FIGURE 16. - UNDERSTANDING OF FIBER-MATRIX INTERDIFFUSION CAN HELP TO MINIMIZE INTERACTIONS.

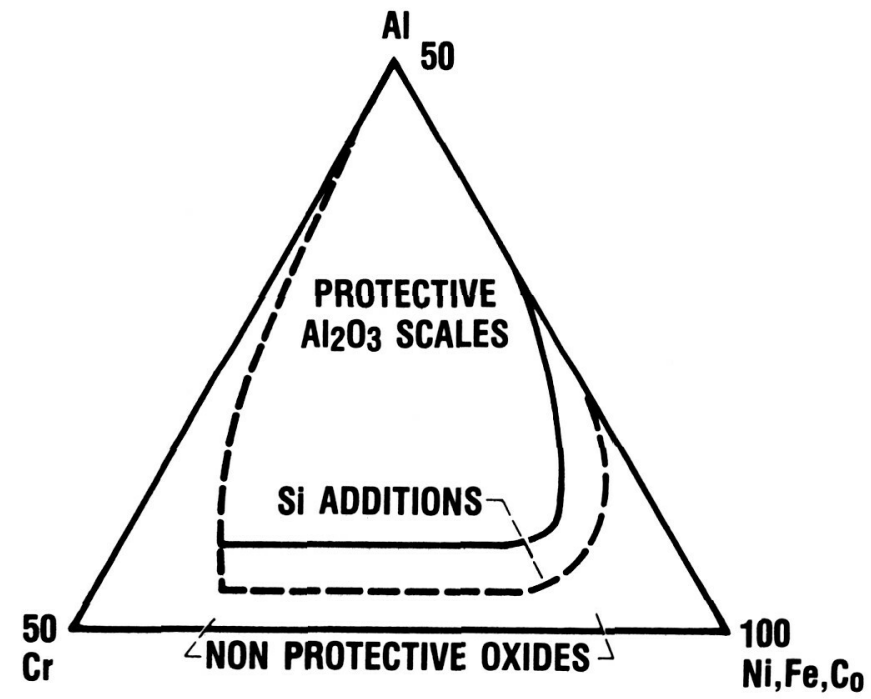

CD-87-26409

FIGURE 17. - UNDERSTANDING OF ALLOYING EFFECTS ON OXIDATION OF INTERMETALLICS IS ESSENTIAL TO THEIR USE AT HIGH TEMPERATURES IN GAS TURBINE ENGINES. 
FABRICATED USING ARC-SPRAY PROCESS INVENTED AT NASA-LEWIS RESEARCH CENTER

- ST300-W - HIGH STRENGTH TUNGSTEN WIRE W/1.5\% ThO 2

- 218CS-W - COMMERCIAL TUNGSTEN LAMP FILAMENT WIRE

\section{MICROSTRUCTURE OF $35 \mathrm{v} / 0$ ST300-W/Nb-1Zr COMPOSITE AT 5OX MAGNIFICATION}

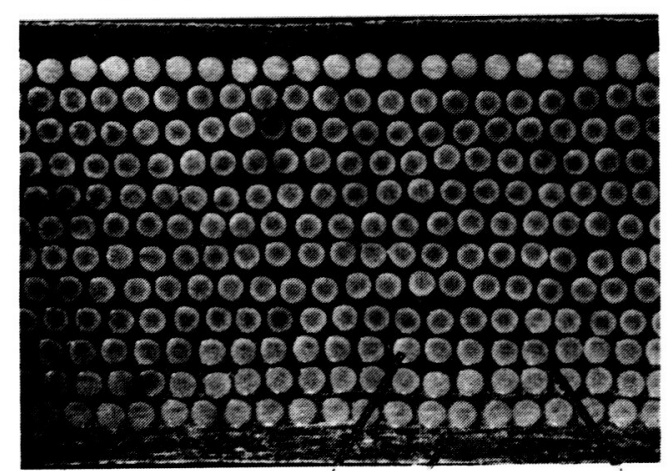

8-MIL TUNGSTEN WIRE

$\mathrm{Nb}$-1Zr CLADDING

\section{COMPARISON OF TENSILE STRENGTH/DENSITY \\ RATIOS OF W/UNALLOYED Nb COMPOSITES WITH CONVENTIONAL Nb ALLOYS}
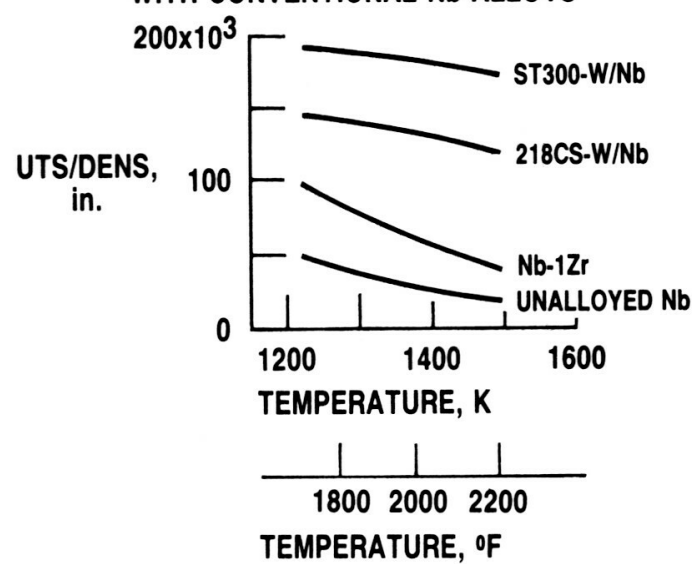

CD-86-18564

FIGURE 18. - REFRACTORY METAL COMPOSITES HOLD PROMISE FOR SPACE POWER SYSTEMS.

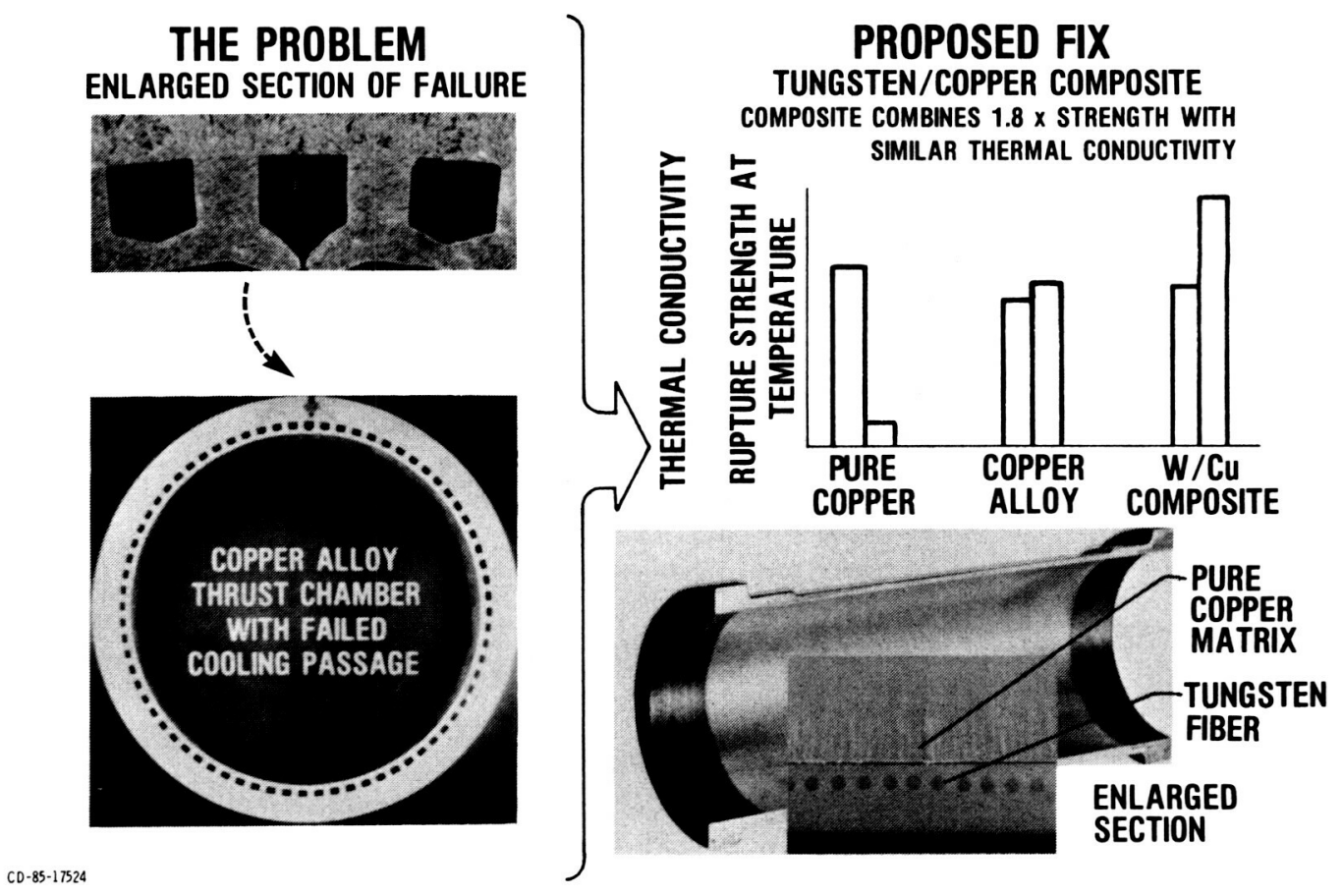

FIGURE 19. - TUNGSTEN REINFORCED COPPER MAY HELP SOLVE COMBUSTION LINER FAILURES IN THE SPACE SHUTTLE MAIN ENGINE. 


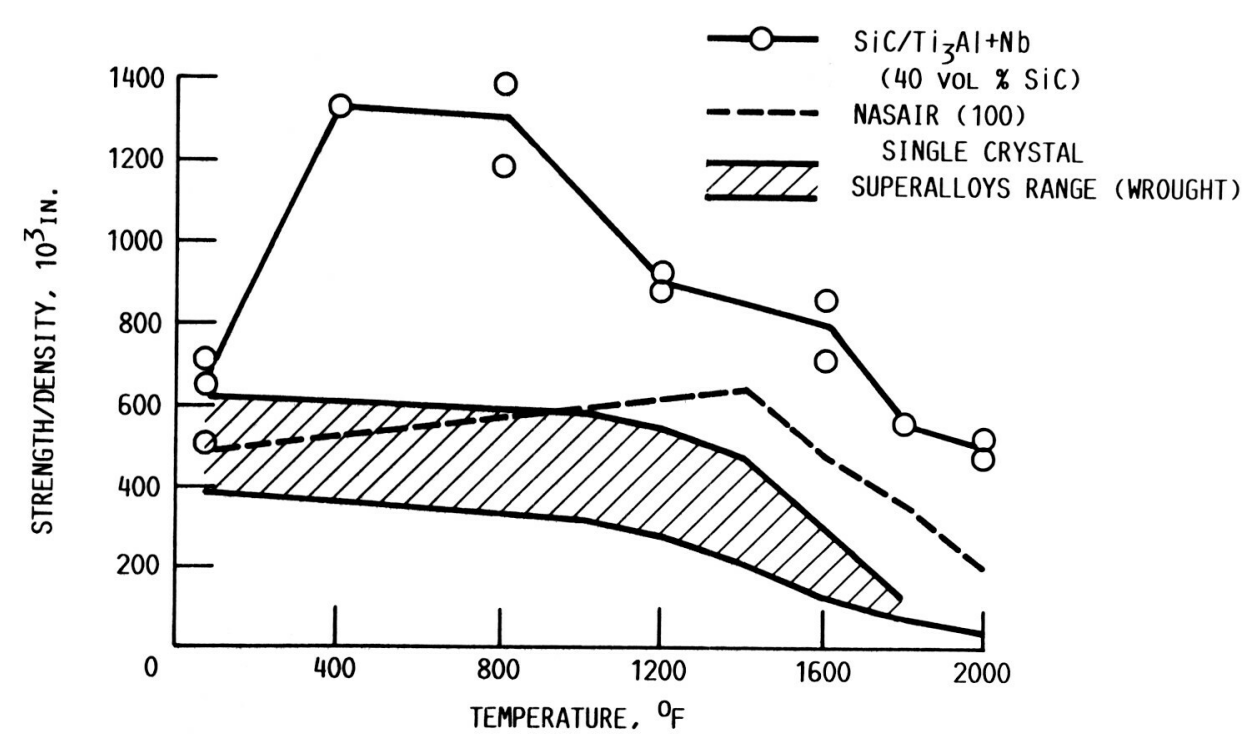

$C 0-87-2759 ?$

FIGURE 20. - LIGHT-WEIGHT SILICON CARBIDE REINFORCED TITANIUM ALUMINIDE COMPOSITES OFFER STRENGTH ADVANTAGES OVER CONVENTIONAL MATERIALS.

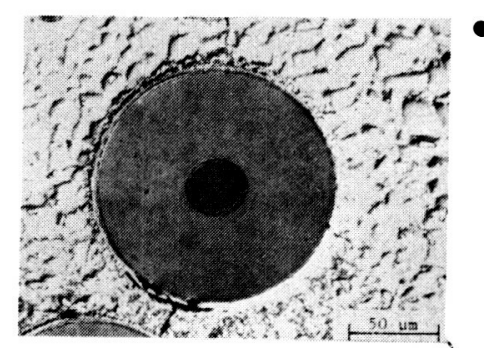

- RESULTS INDICATE FIBER/MATRIX INTERACTION WILL PROBABLY LIMIT USE TEMPERATURE TO $1800{ }^{\circ} \mathrm{F}$ FOR EXTENDED-LIFE APPLICATIONS

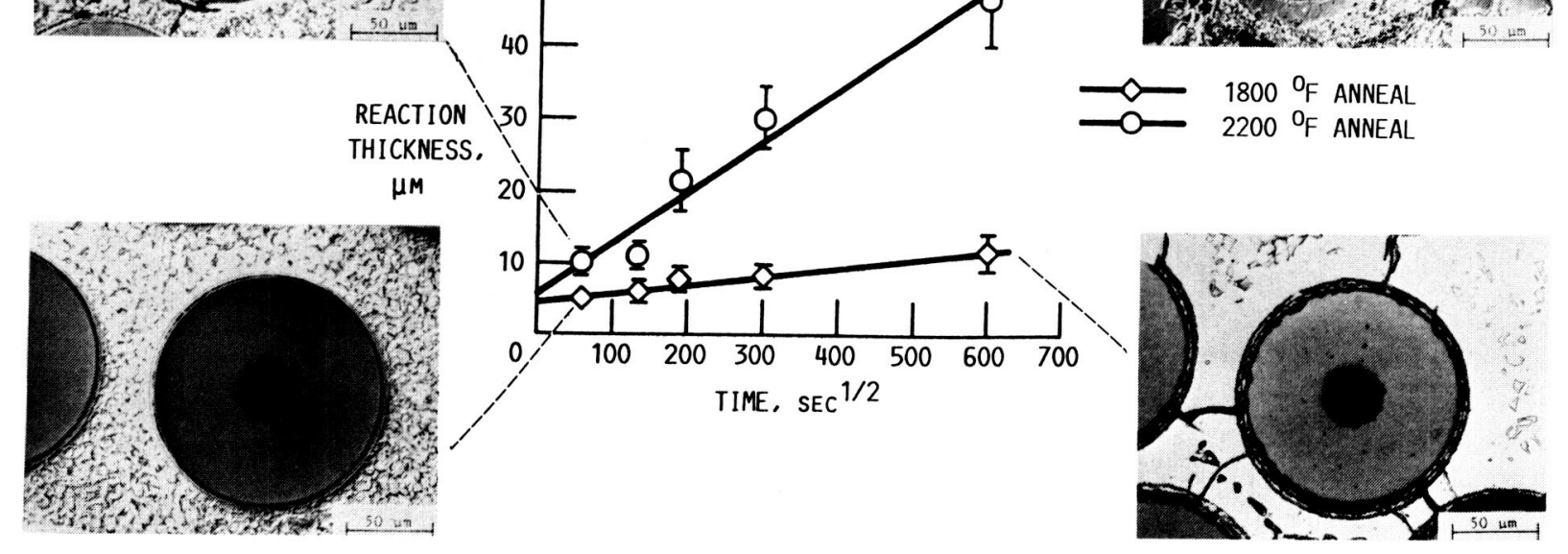

FIGURE 21. - UNDERSTANDING FIBER-MATRIX COMPATIBILITY CAN HELP DEFINE MAXIMUM USE TEMPERATURES OF COMPOSITES. 


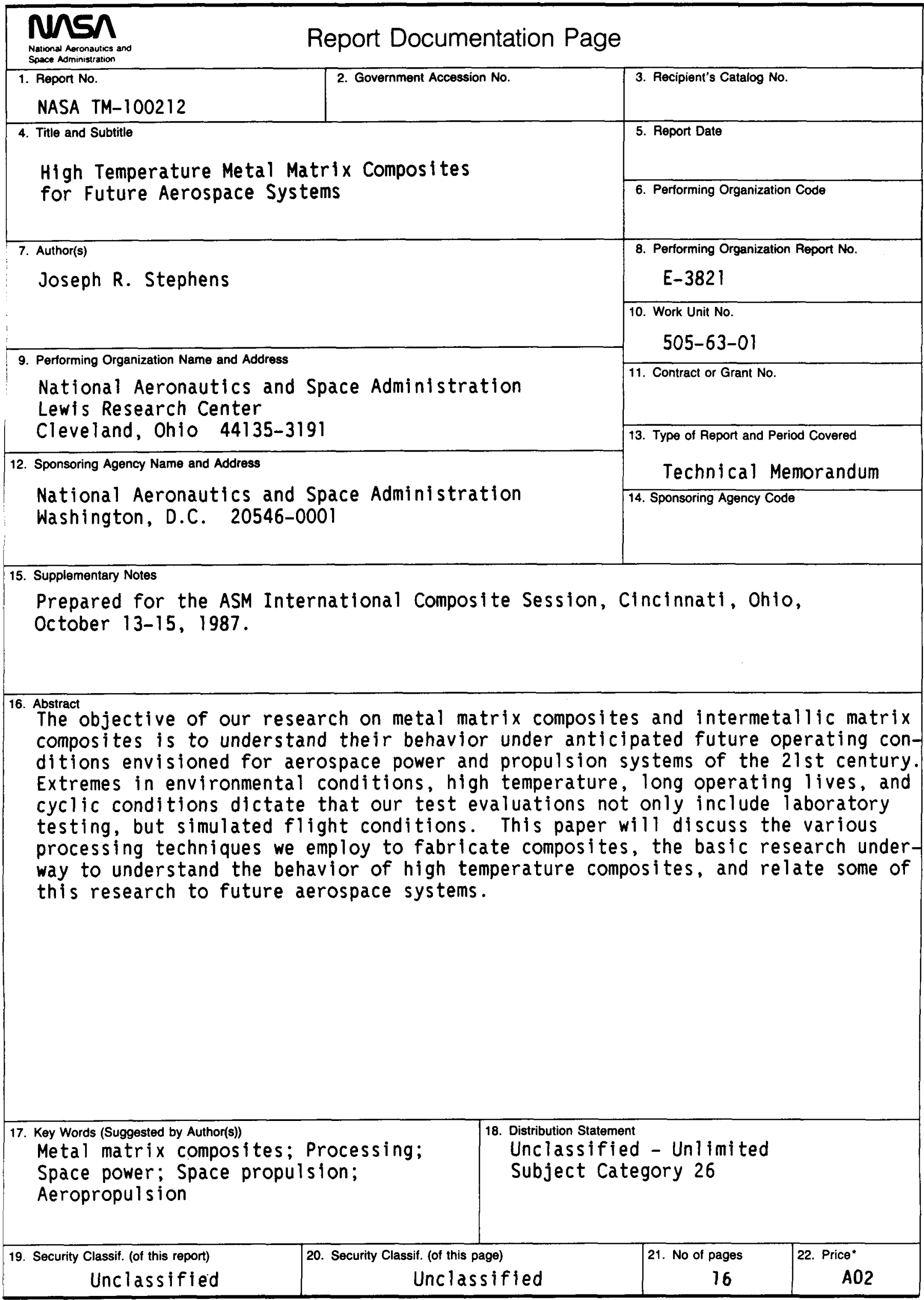

